\title{
The Innovation Process of Teaching Methods Specialized in Universities of Social Studies in Vietnam - Current Situation and Solution
}

\author{
Nguyen Van Hiep ${ }^{(1)}$, Pham Ngoc Tram ${ }^{(2)}$, Ngo Minh Sang $^{\left(3^{*}\right)}$ \\ (1), (2), (3) Thu Dau Mot University (TDMU), Binh Duong, Vietnam \\ *Corresponding author: Ngo Minh Sang, Thu Dau Mot University (TDMU), Binh Duong, Vietnam, E-mail: sangnm@tdmu.edu.vn
}

\begin{abstract}
Innovating university teaching methods in social sciences and humanities is an issue that is always concerned and posed under many different angles at each time and society's requirements. With the historical approach, the system-structure approach, the article analyzes and assesses the current status of teaching methods in social sciences and humanities at university level in Vietnam. On that basis, the article suggests a few solutions to innovate teaching methods such as: renewing faculty thinking in an open direction and approaching advanced teaching methods, improving traditional teaching methods, combine a variety of teaching methods, apply problem-solving teaching, increase the rational use of teaching facilities and information technology to support teaching in the social sciences and humanities university literature in Vietnam.
\end{abstract}

Keywords: innovating methods, humanities and social sciences, university teaching, Vietnam

\section{Introduction}

The innovation of education in general, and the innovation of university teaching methods in particular are the requirements of the society and the country, and is inevitable in historical trends. Education development trends in Vietnam and the world have a strong impact on the innovation of university teaching methods.

The view of the Party and the State reforms education in general and the university teaching methods in particular to create a strong change in education quality and efficiency, to better meet people's learning needs. Innovation must ensure the systematic, comprehensive, basic, long-term vision suitable for each type of object, from the educational level, with synchronous, feasible, focused solutions, key points, appropriate routes and steps; there is an inheritance; developing new factors; to selectively absorb the world's experiences.

\section{Literature Review}

Innovating teaching methods specialized in social sciences and humanities are interested in researching from many different perspectives. In the scope of this explanation, we only ask for permission to point through some perspectives, methods, and research works in foreign countries.

Referring to innovative teaching methods, first of all, Programmer for Internatonal Student Assessment - PISA, 2000 is a program of survey, research, evaluation of teaching and learning in
Germany. Research has shown shortcomings of German education in general, and teaching humanities and social sciences in particular. And this study is likened to a "PISA shock", which has become a boost to German education reform since 2000; and put a heavy burden on the social sciences and humanities in the teaching orientation "capacity building".

Nationnal Curriculum Framework defines the purpose of teaching social science is to improve learners' understanding about society, providing social, cultural, analytical skills to adapt to a rapidly changed world, and interdependently to solve problems in political, economic and social practice. According to Nationnal Curriculum Framework, the teaching of Social Sciences includes three main content circuits: History, Geography, Political Life and Social (Social and Political Life).

Nationnal Curriculum Framework focuses on: 1. Encourage learners to think and help them develop problem solving skills - questioning high thinking skills (HOTs questions); 2. Life skills: critical thinking, effective communication, creativity, civic responsibility, self-awareness, emotional restraint, interpersonal relationships, empathy, observation; 3. Problem solving skills; 4. Ask Value-based questions.

The work Big Ideas History (Oxford University Press) - a history book of big ideas, is assessed very successfully in developing learners' knowledge, understanding and skills and 
connecting ideas directs learners to practice, connect reality, and attach reality to life.

Jochen Huhn in Theoreticsche Grundlagen (Grundlagen Theory - German) argues that historical and social awareness is influenced by the "narrative" view of the historian, journalist, so that leads to difference between real history and historical perception (Jochen, 1995) Jochen Huhn and a number of other scholars (Johann Martin Chladenius) made a "multi-point of view" asking the researcher to be "willing to consider a problem from different points of view" (Ann, 1997), willing to accept that there are different perspectives, different views on past events and phenomena, besides their own views and that these views are equally valid.

Besides, a number of other authors also proposed the innovation of teaching methods, in general, teaching the social sciences of humanities at university level, in particular, scattered in works: Charles C Bonwell and James A. Eison 1991, in Active Learning project (Active Learning); David E. McNabb (2009), Research Methods for Political Science (Research Methods for Political Science); Knottnerus, J. David; Guan, Jian (1997) Analytical Strategies, Developments and Assumptions (Analytical Strategy, Development and Assumptions); Tobias Andersson (2016), Rationality in educational choice - A study on decision-making and risktaking in academic settings - A study on decisionmaking and risk-taking in the environment academic); David R. Shans, Riachard J. Suney and John D. McCarthy (2002), A retest of Probability and reasonable choice, Journal of behavioral decision making; Donatella della Porta, Michael Keat (2008), Approaches and Methodologies in the Social Sciences (Methods, Methodology in Social Sciences).

In Vietnam, research and research on university teaching methods are conducted a lot at universities and research institutes.

Author Nguyen Van Hiep (editor - 2019), Teaching and learning deeply according to the philosophy of active integration, Thu Dau Mot University's manual for higher education in Vietnam, National University of Ho Chi Minh City Publishing House. The work is quite massive, the large format book is 585 pages thick, with 15 chapters and a system of tables and annexes that are quite vivid and easy to understand. In particular, the work devoted a whole chapter, chapter 14 reflecting the content "Innovating teaching and learning in the social sciences and humanities", from pages 528 - 569, with 4 contents (Nguyen, 2019): 1). Develop a teaching model according to a reverse method for students of economics faculty; 2). Online teaching on political theory subjects at Thu Dau Mot University; 3). Apply the model of experience in training students in pedagogy; 4). Innovate English language testing and assessment.

The teaching and learning work follows the philosophy of a positive integration, so the contents of "Innovating teaching and learning in the social sciences and humanities group" are deployed in that direction. This is also a project that we refer to and inherit.

The current popular concept of Vietnamese universities is to equip learners with as much knowledge as possible so that they can have a solid foundation upon graduation, so the role and position of students are not truly focused on. Teaching methods and forms are still quite out of date. The results of a field survey by the National Academy of the United States in 2006 commented on Vietnam's university teaching and learning methods as follows: "Teaching methods are ineffective, too dependent on lectures, and use less active learning skills, resulting in little interaction between students and faculty inside and outside the classroom; too much emphasis on memorization of knowledge without emphasis on conceptual learning or advanced learning (like analysis and synthesis), resulting in superficial rather than intensive learning; students learn passively" (Pham, 2014). According to the author Pham Cong Nhat: "The innovation of teaching methods in universities in our country today is sometimes only superficial. Teaching facilities, such as projectors, videos are only aids to improve teaching quality, the most important thing is the realization that education must be creative and responsible. It is shown through the improvement of methods and curriculum that have not been focused" (Pham, 2014).

Hanoi Pedagogical University (2017), the International Science Conference to train and foster teachers in history to meet the requirements of curriculum and textbook renewal, National University Publishing House, Hanoi. This is a valuable international conference proceedings. 
The books are presented under 4 topics of the seminar, attracting hundreds of domestic and foreign researchers and educators. This work is exploited in the direction of inheriting innovative methods in the social sciences and humanities.

In general, the works emphasize the beneficial role of learners, requiring teachers to create learning opportunities through diverse activities, to stimulate students to explore, to apply, to analyze, and to evaluate ideas; to have active teaching methods, aiming to bring into play the initiative of learners; to build motivation to study and to form lifelong learning habits.

Besides there are many works that are worth reference and comparison for researching the topic: Phan Ngoc Lien - Tran Van Tri (editor 2000), Teaching methods of history, Education Publishing House, Hanoi; Nguyen Ngoc Kha (2015), Innovating teaching methods for political theory subjects according to the approach to scientific competence and pedagogical quality of students of the Ho Chi Minh City Pedagogical University, Journal of Science Ho Chi Minh City University of Education No. 3 (68) in 2015; Ministry of Education and Training (2006), General Education Program. General issues, Education Publishing House, Hanoi; Ministry of Education and Training (2005), Education Development Strategy 2001 - 2010. Education Publishing House, Hanoi; Victor Jakupec - Bernd Meier - Nguyen Van Cuong (2006), High school education development project: Innovating teaching methods towards promoting awareness positivity of high school students. Some examples for the subjects, project product documents of the teaching method experts group.

In general, the works emphasize the beneficial role of learners, requiring teachers to create learning opportunities through diverse activities, to stimulate students to explore, to apply, to analyze, and to evaluate ideas; to have active teaching methods, aiming to bring into play the initiative of learners; to build motivation to study and to form lifelong learning habits.

\section{Results}

\section{Innovating teaching methods}

The activities of renovating university teaching methods in Vietnam have been mentioned and implemented in recent decades. This is a prominent issue that has been mentioned at all times, everywhere and sometimes fiercely in scientific conferences, in newspapers and at many forums of the National Assembly. Teachers and scientists have proposed and proposed solutions to university teaching methods, but the transformation is very slow. Meanwhile, Vietnam's socio-economy is increasingly integrated into the world, emerging many new trends that directly impact the cause of education, as the socialization of open school systems at all levels requires a new human resource, with qualifications and capacities consistent with the country's development and international integration. Schools must compete to attract learners.

Therefore, the university teaching method is suitable for changes in labor nature and content, social needs, and to meet learners' aspirations and conditions. The innovation process must be ensured in the direction of gradually increasing the "grey matter" of learners; develop practice skills and create favorable conditions for job change; enhancing the quality of labor in terms of quality, morality and behavior; increase flexibility, creativity, and adaptability; improve foreign language, computer skills, and social understanding.

Innovating university teaching methods towards promoting students' initiative and creativity (Nguyen, 2011). As when teaching about a certain historical event, the teacher will be able to spend about one or two sessions (sometimes more) just talking about that event. Students not only read books but also watch movies, go to museums that display artifacts or historical relics related to the lesson. Then each student has to find information on the internet, old books, then make an essay to submit to the teacher or make a big poster, stick up pictures and related objects and use it to present to the class. Lecturers should also create conditions for students to group themselves and then write scripts according to a certain historical event and edit films. The incarnation into historical figures makes students feel very excited and very interesting. Certainly, after many years, students cannot forget that history lesson. They will bring the joy and excitement to the next generations of students (Bich, 2015). It is the emphasis on a learning method that maximizes the student's creativity. In any subject, from social sciences to 
nature, students may have to create posters to decorate a subject at the request of the instructor, and the fine arts are also graded. Even good and beautiful posters will be used for teaching or advertising. Each lecturer has each different teaching method. With the same book, but teachers have the right to choose how to teach and freely create methods of imparting knowledge; create conditions for both students and faculty to promote their creativity.

In the context of the current exciting development of science and technology, especially when the economies of many countries develop on the knowledge economic ladder, leading to the phenomenon of "explosion" of information. The amount of human knowledge will increase rapidly over time, so students who have just graduated from the school for 1-2 years are likely to fall behind in their knowledge, especially in the social sciences and humanities. Literature. Therefore, renovating higher education should choose the main "broad" training method, adjust the teaching content, the training time can be shortened. Strengthening the capacity for practical solving for learners, linking the teaching of each subject with equipping learners with the ability to independently solve problems, selfstudy rather than experience in solving practical problems set (Mai, 2020).

Over the years, Vietnam has maintained the view that education must equip learners with as much knowledge as possible to help them have a strong foundation upon graduation to live and practice for a long time. Meanwhile, the educational trend of the advanced countries in the world is that education only needs to teach learners how to solve problems posed in life rather than focus on filling existing knowledge. Therefore, to innovate university teaching methods is to shift from the method of transmitting "as much knowledge as possible" to teaching "problem solving skills set in life". To do that, at present, many universities in Vietnam innovate the university teaching method, focusing on implementing "student-centered", "applying computer in teaching" and applying teaching methods to students get together "group discussion", student-centered under the guidance of the teacher.

Innovation of university teaching methods is a communication process in which the central character, the target of this communication process, is the learner. All factors related to the teaching / learning process are oriented towards individual perfection of learners through acquiring knowledge, training skills and forming learners' personality.

Innovating university teaching methods is not only about using active teaching methods to improve the quality of training, but also must know how to apply and combine skillfully some techniques and skills such as teamwork; conversation; play as a character; presentation; brainstorming, to achieve efficiency and goals of new teaching methods.

\section{Some solutions}

Renew teachers' thinking towards openness and approach advanced teaching methods. Innovating the university teaching method is to change the approach and method of organizing the training process, starting from perception to actual action. First of all, the innovation of teaching methods must be based on the innovative thinking of teachers in the direction of opening and approaching advanced teaching methods.

"Opening" is not framed in the old way of thinking, the old teaching method (as mentioned in the previous sections), but in the direction of modernity, with the following objectives: 1 . Mastering scientific knowledge and scripture. Life experience: Learn to know; 2. Mastering practical skills (performance capacity) to become creative workers: Learn to do; 3. Form the ability to integrate into the community and work cooperatively: Learn to live together; 4 . There is a will to rise up to assert themselves in a modern world and science and technology develop rapidly as a storm: Learn to assert yourself (Phung, 2008).

Advanced university teaching methods must be organized on a learner-centered basis, an objective that needs to have a transformative impact while emphasizing that learners are also cognitive subjects and the main resource of the teaching process. Students 'activeness, initiative and creativity must be appreciated, the teaching process must exploit all potentials, promote the students' activeness, initiative and creativity (Phan, 2013).

The essence of the advanced, learner-centered university teaching method is to chemical learners, maximizing the capacity of each individual in a favorable collective environment. 
The advanced university teaching method is to switch from the dominant teaching method, which is almost exclusively on the current university lecture halls, to the combined use of other forms of teaching organization (Nguyen, 2020):

+Take self-study of individuals as the foundation.

+Organize group study to support each individual.

+ Perform regular viewinar to enhance research.

+ Organize practice of subjects.

+ Improve the quality of pedagogical practice.

+ Organize scientific research activities.

Advanced university teaching methodology is to move from the teaching method of monologue to a method of all participation, with multimedia techniques, with specific methods such as:

-Brainstorming method is a teaching method in which the lecturer raises problems, students think, freely raise their own ideas. The purpose is to stimulate thinking, find ideas to solve problems.

-Group discussion is a collective learning method. This method provides an opportunity for each student to speak and share their perspectives, to master learning issues together. There are many techniques for organizing group learning.

-Role-learning is a method of reproducing reallife situations, role-playing students, through which students show reasonable views, attitudes and behaviors.

-Project method, students discuss and develop research projects and propose solutions and carry out implementation.

-Organized many activities of practice, study, practice of research, training of pedagogical skills according to technical expertise from low to high training, combining internal and external courses, with compulsory or optional content.

Improve traditional teaching methods. In the current context, improving traditional teaching methods is to improve test and assessment (focus on regular assessment) and reform the way curriculum and teaching outlines to achieve new training goals. Lecturers must know different teaching methods depending on the circumstances: lecturing, discussing, experimenting, problem solving, giving presentations, doing project or project design, research, simulation. Lecturers must guide students to practice their cognitive abilities, creative thinking capacity, information gathering capacity, information processing capacity, teamwork capacity, and ability to self-study and learn more. Teachers must train students' humanities with their own qualities through professional passion and enthusiasm to teach through proficient use of a number of technical pedagogical methods.

Although lectures are typical and traditional teaching methods of schools, teaching methods for small groups need to focus on training, to teach self-study. For the purpose of teaching is not only imparting extensive content or specialized skills, but also helping students develop the ability to analyze reason and create creative problem solving, and help students build confidence with self-study and development.

Lecturing is a traditional teaching method, the purpose of lecturing is mainly to convey information and knowledge, promote thinking to learn the lecture, create excitement to learn. But these goals are not always relevant, and the teacher is not necessarily interested in achieving all three equally. Being too concerned with communicating sufficient information and knowledge can limit understanding. Too much emphasis on clarification may have to deliberately leave out the details. On the other hand, too interested in creating interest may not be enough time to fully understand.

Improving, or renewing teaching - a typical and traditional teaching method - is to focus more on small group teaching methods, personalize teaching and learning to improve the quality of training; promotes interaction and self-discovery. This method is very suitable for the long-term purpose of developing creative independent thinking, analytical thinking, ability to evaluate, adjust and apply the knowledge learned of students.

In the process of improving traditional teaching methods, it is necessary to achieve the following main objectives:

+ Develop the ability to learn, analyze, evaluate, judge, and solve problems.

+Increase understanding, sensitivity and creativity, promote changes in attitudes and behaviors.

+Improve verbal presentation capacity and interactive communication skills with others

+Train ability to work collectively. 
In short, improving traditional teaching methods, requiring teachers to master the requirements and use their techniques proficiently in preparation and promotion, such as introduction technique, presentation techniques, and explanations during a presentation, questioning and answer processing techniques in conversation, or modeling techniques in practice (Center for the Development of Pedagogical Skills, 2016). However, traditional teaching methods have inevitable limitations, so in addition to traditional teaching methods, it is necessary to combine the use of new teaching methods, especially methods and teaching techniques to promote students' positivity and creativity.

Combining a variety of teaching methods. The combination of diverse teaching methods and forms in the entire teaching process is an important direction to promote positivity and improve teaching quality (Cao, 2020).

Classroom teaching, group teaching, group teaching and individual teaching are social forms of teaching that need to be combined with each other, each with its own functions. The form of teamwork is very diverse, not only limited to solving small learning tasks alternating in presentations, but also forms of teamwork dealing with complex tasks, which can occupy one or more lessons, using specialized methods such as role-play, case studies, and projects.

Applying problem solving teaching. Problem solving teaching is a teaching perspective aimed at developing thinking capacity, cognitive ability and problem solving. Learning is placed in a problem situation, which is a situation containing cognitive conflict, through problem solving, helping students to acquire cognitive knowledge, skills and methods. Problem-solving teaching is a fundamental pathway to promote students' cognitive positivity, which can be applied in many forms of teaching with different levels of student self-reliance. Problem situations are specialized scientific situations, which can also be situations associated with reality.

\section{Applying teaching by situations}

Situational teaching is a teaching perspective, in which teaching is organized according to a complex theme associated with real life and professional situations. The learning process is organized in a learning environment that enables students to build knowledge individually and in the social interaction of learning.

The case study method is a typical teaching method of case-based teaching, in which students solve a typical situation by themselves, associated with practice through teamwork

Applying teaching in real-life situations is an important way to associate training in schools with real life, contributing to overcoming the situation of academic education, away from the current practice of the university.

The limitation of this method, which is put into teaching is simulated situations, not real situations.

Apply action-oriented teaching. Action-oriented teaching is a teaching perspective that aims to make mental and physical activities work together. During the learning process, students perform learning tasks and complete action products, with a flexible combination between intellectual and physical activities (Nguyen, 2007).

This is a positive and harmonious teaching perspective. Action-oriented teaching has important implications for the implementation of educational principles combining theory with practice, thinking and action, school and society.

Project-based teaching is a typical form of actionoriented teaching, in which students perform in groups a complex learning task, linked with practical problems, combining theory and practice, have created publishable products. In project-based teaching, many modern teaching theories and perspectives can be applied such as constructivist theory, student-oriented teaching, collaborative teaching, integrated teaching, discovery teaching, and creativity. , case-based teaching and action-oriented teaching (Nguyen \&Hoang, 2020).

Increase the rational use of teaching facilities and information technology to support teaching. Teaching facilities play an important role in innovating geography teaching methods in order to enhance visualization, experimentation, and practice in teaching. The use of teaching facilities should be consistent with the relationship between teaching facilities and teaching methods.

Multimedia and information technology are both teaching content and teaching medium in modern teaching. Multimedia and information technology have many applications in teaching.

In addition to using multimedia as a means of demonstration, it is necessary to increase the use 
of teaching software as well as teaching methods using electronic networks (E-Learning) ( $\mathrm{Vu} \&$ Nguyen, 2019).

New teaching facilities also aid in finding and using new teaching methods. Webquest is an example of a new teaching method with a new means of teaching using electronic networks, in which students discover knowledge online in an orientation (Bui, 2018).

Use positive and creative teaching techniques. Teaching techniques are ways of acting of teachers, teachers and students in small action situations to implement and control the teaching process.

Pay attention to the specific teaching methods of the subject. Teaching method has a dialectic relationship with teaching content. So, beside the general methods that can be used for many different subjects, the use of specific teaching methods plays an important role in teaching the subject. Subject-specific teaching methods are built on the basis of subject teaching theory.

Fostering positive learning methods for students. Self-reliant learning method plays an important role in actively promoting and promoting students' creativity. There are common cognitive methods such as methods of gathering, processing, evaluating information, methods of organizing work, methods of teamwork, and there are specialized learning methods for each subject. In many different ways, it is necessary to practice students with common learning methods and learning methods in the subject.

\section{Conclusion}

Innovating university teaching methods in social sciences and humanities is an issue that is always concerned and posed under many different angles at each time and society's requirements. Today, that requirement is posed more urgently

\section{References}

1. Ann, L. (1997). The Council of Europe and School History, Strasbourg, Council of Europe, p.54-55.

2. Bich, L. (2015). Renewing History: It is necessary for learners to have the national spirit. Retrieved from https://vov.vn/xahoi/giao-duc/doi-moi-mon-lich-su-phai-de- because Vietnam's higher education is still lagging in many ways compared to the world development level. Most lecturers in class still use outdated teaching methods, do not create excitement for students, teachers impart knowledge to learners in one-way relationships, learners are passive in acquiring. In addition, higher education innovation also faces barriers, such as conservatism, stagnation in awareness, interests in innovation, or the lack of modern higher education faculty and knowledge of lecturers. In addition, the current rate of class time students is too high, time for self-study is limited. The number of classrooms is lacking, there are very few classrooms designed to have specific use functions, thus limiting multidimensional interaction in the classroom. The poor working conditions of lecturers, teaching equipment, internships, and scientific research also cause difficulties for innovation. The specific program objectives of each discipline and each module have not been paid enough attention, leading to the focus on knowledge by lecturers without adequate attention to teaching skills and professional qualities to students.

Innovating university teaching methods with different approaches, requiring appropriate facilities, facilities and teaching organization, and organizational and management conditions. In addition, the teaching method is also subjective. Each instructor with his or her own experience needs to identify individual directions for improving teaching methods and personal experience.

\section{Acknowledgement}

All authors contributed equally to the conception and design of the study.

nguoi-hoc-co-duoc-tinh-than-dan-toc453529.vov, December 31, 2020.

3. Bui, L. D., Nguyen, V, N., Ho, T. T. H., Tran, T. T., \& Bui, L. D. T. (2018). Application of information technology and communication in teacher training: Practical experience at the Faculty of Education, Can Tho University. 
Can Tho University Journal of Science, 54 (7): 130. DOI: 10.22144 / ctu.jvn.2018.133.

4. Cao, T. T. (2016). Applying innovative teaching methods of social sciences in high schools: Case study of high schools in Dong Thap province. Conference: The 3rd Malikhaing Guro International Conference on Culture-based Education (Innovative Education and Cross Cultural Human Resource Development), Ho Chi Minh City, 26th-27th October, 2016 (International conference proceedings), ISBN: 978-604-734651- 6, 156-165.

5. Jochen, H. (1995).Theoreticsche Grundlagen, Bonn, p25- 26.

6. Mai, T. T. D. (2020). Teaching for creative capacity development in the general education program 2018 (Teaching for

10. Nguyen, T. H., \& Hoang, V. H. (2020). Develop research skills for learners through project-based teaching. Retrieved from http://www.quangninh.gov.vn/so/sogiaoducda otao/Lists/TinTuc/Attachments/4058/Day\%2 0hoc\%20theo\%20Du\%20an.doc.

11. Pham, C. N.(2014). Renovating higher education towards international integration in our country today. Retrieved from http://tapchicongsan.org.vn/web/guest/chitiet-tim-kiem/-/2018/30373/\%C4\%91oi-moigiao-duc-\%C4\%91ai-hoc-theo-huong-hoinhap-quoc-te-o-nuoc-ta-hien-nay.aspx

12. Phan, T. H. X. (2013). Innovating the "Learner-centered" teaching method through the experience of the National Institute of Education Singapore. Thu Dau Mot University Journal, No. 2 (9).

13. Phung, T. P. (2008). Community-serving learning - innovative teaching and learning methods at HCMC University of Science. Scientific Workshop "The initiative of thinking, methods and university spirit" - Hoa Sen University HCMC.

14. Center for Development of Pedagogical Skills - Ho Chi Minh City University of Pedagogy. (2016). Some methods to innovate teaching methods. Retrieved from http://hcmup.edu.vn/index.php?option=com content $\&$ view $=$ article $\&$ id $=22038 \% 3$ A2016$10-31-02-02-15 \&$ catid $=5510 \% 3$ A2016-0729-02-30-
Creative Competence in General Education Program 2018). VNU Journal of Science: Education Research, [S.1.], v.36, n.2, june. DOI: https://doi.org/10.25073/25881159/vnuer.4375

7. Nguyen, T. T. H. (2007). Using project teaching methods in organizing vocational education activities. Journal of Education, No. 179, 2007, p. 21-22.

8. Nguyen, N. H. (2020). Modern teaching methods applied in training by the credit system. Retrieved from http://ltvu.edu.vn/news/detail/354/22-ahrefhttp-ltvueduvn-news-detail-354-22.

9. Nguyen, T. C. V. (2011). Promote the activeness and initiative of students through self-directed learning activities. Saigon University Jourmal, Book No. 6, 06/2011. $02 \&$ Itemid $=9426 \&$ lang $=$ vi\&site $=237$, December 31, 2020.

15. Vu, T. G., \& Nguyen, H. N. (2019). Blearning: A Suitable Learning Modality for Higher Education in Vietnam at Digital Age. Journal of Science - Hanoi Pedagogical University. DOI: 10.18173 / 2354-1075.20190017. 